\title{
Computer Modeling of Detonators*
}

\author{
Carlton M. Furnberg \\ Sandia National Laboratories / California \\ Livermore, CA 94551-0969 USA
}

\begin{abstract}
A mathematical model of detonators which describes the resistance of the exploding bridgewire or exploding foil initiator as a function of energy deposition will be described. This model includes many parameters that can be adjusted to obtain a close fit to experimental data. This has been demonstrated using recent experimental data taken within Sandia National Laboratories.
\end{abstract}

\section{INTRODUCTION}

High energy detonators have been used for various purposes in weapon designs over the years. One type uses an exploding wire, typically gold, to initiate the explosive material surrounding the wire. The wire, which has dimensions on the order of 1.5 mils $(0.0015 \mathrm{inch})$ in diameter by 10 mils in length forms a bridge between two large conductivê posts. Energy is delivered to the detonator at a high rate from a high voltage source causing the bridgewire to explode within a fraction of a microsecond at a current level of hundreds to thousands of amperes. The resistance of the exploding bridgewire (EBW) is extremely nonlinear during the firing process, starting out very low, milliohms to tens of milliohms, and peaking at a maximum value on the order of a few ohms, and then decaying to a value which is typically significantly higher than its initial resistance. Another type of detonator uses an exploding foil initiator (EFI), a portion of a flat copper cable which is reduced in width for a short distance at the detonator and explodes when a large firing current is delivered. This EFI accelerates adjacent insulation material to a high velocity which impacts upon a nearby explosive pellet causing detonation. The EFIs typically, but not always, require more energy to fire than the EBWs but have similar resistance characteristics starting initially at a few milliohms, peaking at a value in the hundreds of milliohms, and then decaying to a value in between the two extremes. Time of EBW/EFI "burst" is defined as the time of maximum resistance.

Until recently, most of the computer modeling of detonators within Sandia National Laboratories used "look-up" tables based upon experimental data obtained many years ago using high voltage, coaxial cable, discharge systems. This test circuit provides an adjustable, constantcurrent source with a fast rise time that is ideal for obtaining the electrical characteristics of EBWs/EFIs. Unfortunately the old data do not characterize well the resistance of the EBW/EFI after time of burst since this time regime was thought to be of less importance. However, to determine operating margins for the energy delivery system, it is important to accurately model the resistance over the entire time of operation.

New data have recently been taken by G. R. Peevy and W. P. Brigham, Sandia National Laboratories / New Mexico, using a cable discharge system [1] and modern instrumentation, to provide accurate information on old and new detonators until well after EBW/EFI burst. The constant current through the EBW/EFI and the voltage developed across the EBW/EFI are digitized at one-nanosecond intervals for the width of the current pulse, approximately three microseconds. These data are used to provide plots of EBW/EFI resistance as functions of the energy absorbed and the action (time integral of the current squared) delivered.

Figs. 1 and 2 show the resistance of an EBW and an EFI respectively as a function of energy absorbed using data taken with the cable discharge system. A mathematical model has been developed which describes this resistance vs. energy behavior.

$1.5 \times 10$ Mil Gold EBW Detonator Tested at 300 Amperes

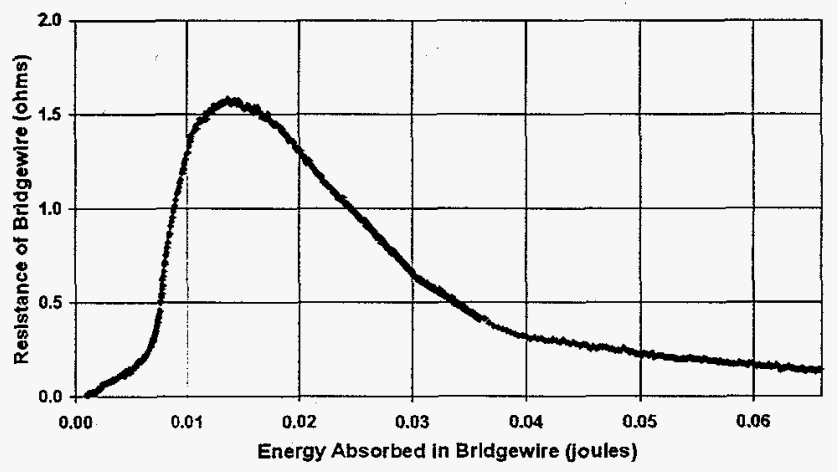

Fig. 1. Resistance as a function of energy for an EBW

*This work was supported by the United States Department of Energy under Contract DE-ACO4-94AL85000.

\section{MASTER}

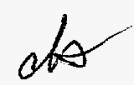




\section{DISCLAIMER}

Portions of this document may be illegible in electronic image products. Images are produced from the best available original document. 
$20 \times 20 \times 0.2$ Mil EFI Detonator Tested at 3,800 Amperes

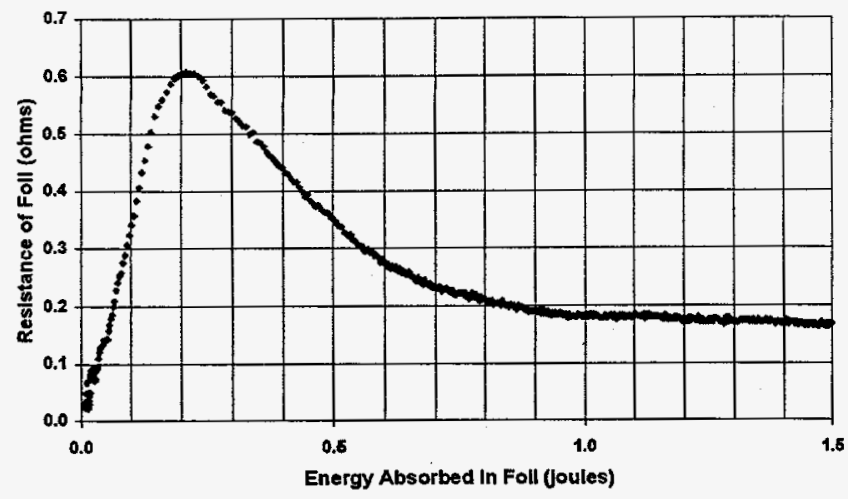

Fig. 2. Resistance as a function of energy for an EFI

\section{EXPERIMENTAL DATA}

The experimental data from the cable discharge system show that the resistance behavior of an EBW/EFI depends upon the rate of energy delivery, or, in other terms, the current level used in obtaining the data. As the current level is increased, the energy absorbed in the EBW/EFI at time of burst increases significantly while the action delivered at time of burst increases to a much lesser extent. Also the peak resistance decreases as the current level is increased. Therefore, to accurately model a particular EBW/EFI over a range of firing or burst currents, several models are required. Generally, experimental data are taken at three different current levels for a particular detonator, nominal operating burst current, threshold burst current (that current at which $1 / 2$ of the detonators would fire), and a burst current midway in between.

\section{MATHEMATICAL MODEL}

The mathematical model of the resistance vs. energy behavior of an EBW/EFI consists of two equations. The first equation applies from zero input energy until slightly after the energy at which burst occurs while the second equation applies for higher energies.

The first equation, or "early" model, consists of the initial resistance and a Gaussian function with a zero offset correction:

$$
\text { (1) } \mathrm{R}=\mathrm{R} 0+\mathrm{AB}^{*}\left(\exp \left(-((\mathrm{G}-\mathrm{G} 0) / \mathrm{AS})^{2}\right)-\mathrm{Z} 01\right)
$$

where $\mathrm{R} 0=$ initial resistance (ohms), $\mathrm{AB}$ controls the height of the resistance peak, $G=$ energy absorbed (joules), $\mathrm{G} 0=$ energy absorbed at burst (joules), AS controls the function width, and Z01 = zero offset correction which makes the Gaussian function $=$ zero when $G=$ zero.
The second equation, or "late" model, is a decaying exponential:

$$
\text { (2) } \mathrm{R}=\mathrm{R} 0^{*} \exp \left(-\mathrm{G} /\left(\mathrm{N}^{*} \mathrm{G} 0\right)\right)+\mathrm{K}
$$

where

$\mathrm{R} 0^{\prime}=\left(\mathrm{AB} *\left(\exp \left(-(((\mathrm{SWPT}-1) * \mathrm{G} 0) / \mathrm{AS})^{2}\right)-\mathrm{Z} 01\right)+\mathrm{R} 0-\mathrm{K}\right)$ ${ }^{*} \exp (\mathrm{SWPT} / \mathrm{N})$, and $\mathrm{K}=$ resistance (ohms) when $\mathrm{G}=$ infinity. $\mathrm{N}$ controls the exponential decay rate while SWPT provides the capability to move the intersection point of (2) with (1) to provide a better fit to the experimental data.

To model the resistance of a particular detonator one must determine its model parameters using experimental data, except for parameter $\mathrm{R} 0$ which can be calculated knowing the EBW/EFI dimensions and material. The other parameters, $A B, A S, G 0, K, N$, and SWPT are determined by trial and error. Since a perfect match to experimental data cannot be accomplished, a practical knowledge of which parameters are more important is helpful. Good results are obtained by fixing the initial resistance, $\mathrm{R} 0$, energy at burst, $\mathrm{G} 0$, and peak resistance (controlled by $A B$ ) while $A S, K, N$, and SWPT are varied to obtain the best visual fit to the experimental data. It should be noted that there is an interdependency between some parameters which must be taken into account. For example, changing $\mathrm{AS}$ will require a change in $\mathrm{AB}$ in order to maintain a constant peak resistance.

While parameters can be chosen to give a very good visual match to experimental results ( $R$ vs. G), the detonator model can have a serious flaw unless the action at burst is also taken into account in choosing the parameters. If the action at burst is not matched to the experimental value, EBW/EFI burst will occur at the wrong time giving erroneous results. With initial resistance and peak resistance fixed, AS is the parameter which must be chosen carefully to match the experimental value of action at burst. In some cases this will result in a visual match to the experimental data that appears less than optimum but, in reality, will provide a more accurate model. On occasion, as a last resort, when a good match with the action at burst cannot be obtained by simply adjusting AS, small increases can also be made to R0 to obtain the desired match without significantly affecting computer simulation results.

\section{IMPLEMENTATION OF MODEL}

These equations have been implemented for computer simulation using the electrical circuit simulator PSpice [2]. Changing from the first equation to the second equation is accomplished within the simulator with switches controlled by the energy at burst. Care was taken to minimize the discontinuity which naturally occurs at time of switching. 


\section{COMPARISON TO EXPERIMENTAL DATA}

Fig. 3 is a plot of the equations (complete equations not shown) used to model the resistance vs. energy behavior of the 1.5 mil diameter $x 10$ mil long gold EBW shown in Fig. 1 while Fig. 4 is a plot of the equations used to model the resistance vs. energy behavior of the $20 \times 20 \times 0.2 \mathrm{mil} \mathrm{EFI}$ shown in Fig. 2. The energy at burst, action at burst, and peak resistance in the mathematical models match the experimental data precisely while excursions from the experimental data in other areas are small creating very good computer models. Switching from the Gaussian equation to the decaying exponential equation (controlled by parameter SWPT) occurs at 105 percent of burst energy for the EBW and at 107 percent of burst energy for the EFI.

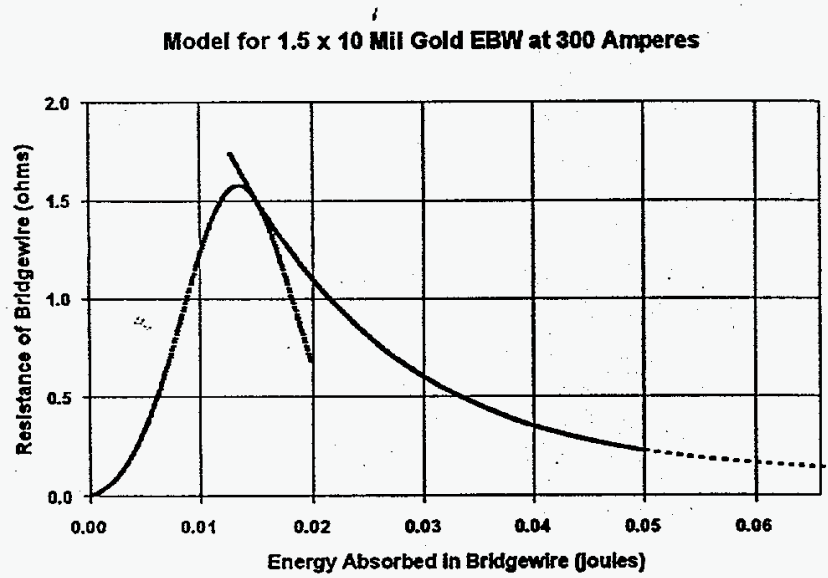

Fig. 3. Plot of equations used to model EBW

Model for $20 \times 20 \times 0.2$ Mil EFI at 3,800 Amperes

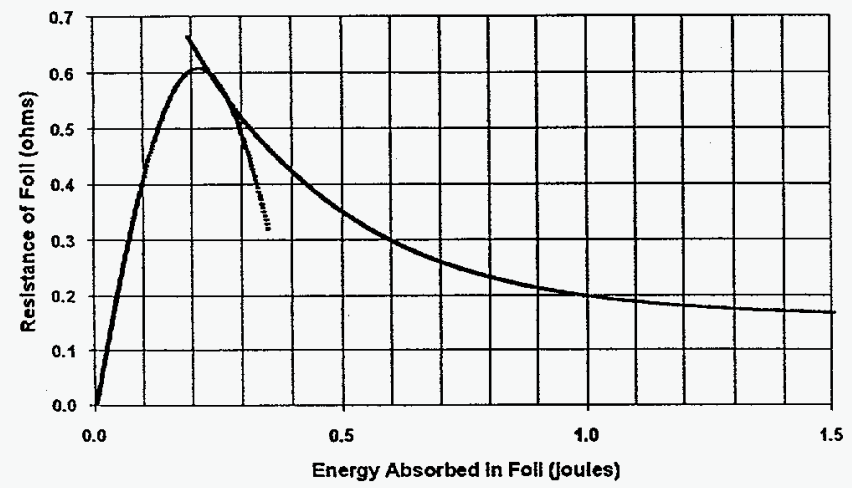

Fig. 4. Plot of equations used to model EFI

Figs. 5 and 6 are plots of resistance vs. energy for the EBW and EFI taken from PSpice computer simulations using the mathematical models illustrated in Figs. 3 and 4 . The observed discontinuities at time of switching between models have no appreciable effect on the accuracy of the simulation due to their very short duration.

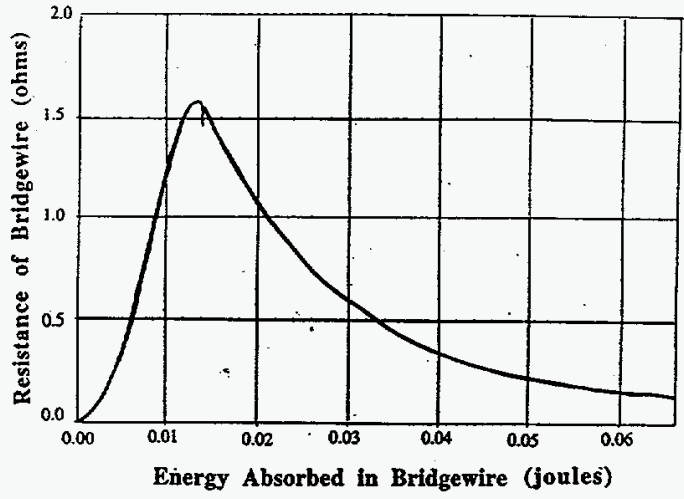

Fig. 5. PSpice computer simulation for EBW

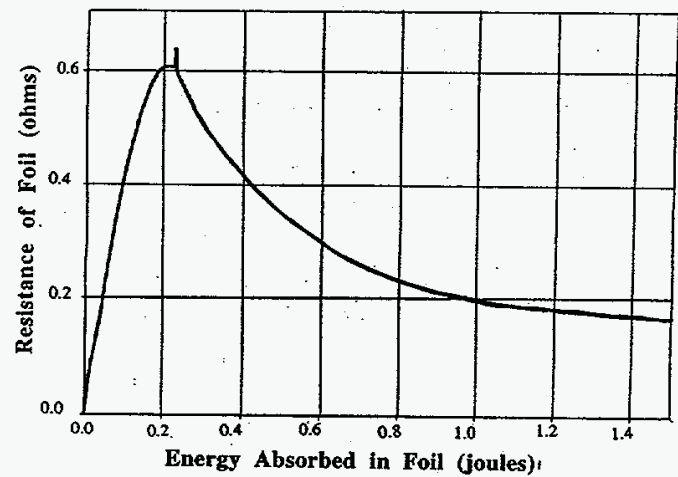

Fig. 6. PSpice computer simulation for EFI

Accurate computer models for many EBWs and EFIs of various sizes and materials have been created using the mathematical models described in this paper. Much of the success is attributed to the flexibility provided by the large number of parameters that can be adjusted to closely approximate the experimental data. Also, the ability to diride the resistance behavior into two energy regimes described by different equations, which the electrical circuit simulator can switch between, has been very helpful.

\section{MATHEMATICAL MODEL VS. LOOK-UP TABLE}

One might question the usefulness of a mathematical model for the resistance of an EBW/EFI when a look-up table can be constructed from the original experimental data and readily implemented into an electrical circuit simulator. The major advantage of the mathematical model over the look-up 
table is the ease with which "what if" or "worst case" analyses can be performed. One parameter that one likes to adjust for analysis of detonator firing circuits is $\mathrm{G} 0$, the energy at burst. This can easily be done with the mathematical model but can be a formidable task when using a look-up table. Also, the mathematical model provides a compact description of any detonator using just seven parameters while the look-up table may contain hundreds of individual data pairs, depending upon the desired accuracy.

\section{SUMMARY}

A mathematical model for the resistance of high energy detonators as a function of energy absorbed has been described. This model uses two equations with seven parameters that can be chosen to closely fit experimental data. The first equation applies to the energy regime until slightly after EBW/EFI burst while the second applies for higher energies. These equations have been implemented using the electrical circuit simulator PSpice. Switching between equations is accomplished within the simulator. Accurate computer models for many EBWs and EFIs have been created using the mathematical model described.

\section{REFERENCES}

[1] G. R. Peevy, S. G. Barnhart, and W. P. Brigham, "Cable discharge system for fundamental detonator studies", presented at the NASA Aerospace Pyrotechnic Systems Workshop, February 1994, to be published.

[2] PSpice (a registered trademark of) MicroSim Corporation, 20 Fairbanks, Irvine, California.

\section{DISCLAIMER}

This account of work sponsored by an agency of the United States United States Government nor any agency thereof, nor any of their Government. Neither the United States Government nor any as any legal liability or responsiemployees, makes any warranty, express or implied, or assum anytion, apparatus, product, or bility for the accuracy, completeness, or usefulness of any infore privately owned rights. Referprocess disclosed, or represents that its use would not infre prive by trade name, trademark, ence herein to any specific commercial product, process, or ser imply its endorsement, recommanufacturer, or otherwise does not necessarily constitute or imply its endorseof. The views mendation, or favoring by the United States Government or any agency reflect those of the and opinions of authors expressed herein do not

United States Government or any agency thereof. 